Josette Daemen*

\title{
What (If Anything) Can Justify Basic Income Experiments? Balancing Costs and Benefits in Terms of Justice
}

https://doi.org/10.1515/bis-2021-0024

Received June 11, 2021; accepted June 11, 2021

\begin{abstract}
The central thesis of this essay is that basic income experiments are justified if their expected benefits in terms of justice exceed their expected costs in terms of justice. The benefits are a function of basic income's effect on the level of justice attained in the context in which it is implemented, and the experiment's impact on future policy-making. The costs comprise the sacrifices made as a result of the experiment's interventional character, as well as the study's opportunity costs. In light of the proposed standard of justification for basic income experiments, the factors that play a role in it, and the way these interact with one another, this essay provides some practical recommendations for researchers hoping to conduct such an experiment.
\end{abstract}

Keywords: basic income experiments, justice, cost-benefit analysis, evidencebased policy

\section{Introduction}

Twenty-five years have now passed since Van Parijs (1995) asked a question that would gain wide fame in the world of political philosophy: "what (if anything) can justify capitalism?" The answer he gave to this question, however, would become famous even beyond the political philosophy community: the institution of an unconditional basic income (UBI). ${ }^{1}$ The idea has been around for longer, but over the past quarter of a century the interest in UBI has surged to unprecedented levels both among academics and the wider public.

1 The terms "basic income", "unconditional basic income", and "UBI” are used interchangeably throughout this text. They are taken to cover any scheme in which periodic cash payments are delivered to all universally and unconditionally, so without a means-test or work-requirement.

*Corresponding author: Josette Daemen, Institute of Political Science, Faculty of Social and Behavioural Sciences, Wassenaarseweg 52, 2333 AK Leiden, The Netherlands,

E-mail: j.a.m.daemen@fsw.leidenuniv.nl 
Looking at the extensive theoretical literature on UBI, one could say that most contributions revolve around the question: "what (if anything) can justify basic income?" In answering this question, both positively and negatively, political philosophers have considered UBI in light of a wide range of different values: freedom, equality, reciprocity, and democracy, to name only a few. However interesting and important it is to analyse the connection between these concepts and the idea of UBI in theory, any philosopher truly committed to these ideals should also be curious to find out whether implementing UBI would actually contribute to their realisation in practice. But the rub is that we are currently still lacking real-world examples of fully developed basic income schemes that could show us to what extent the policy delivers on its high promises (De Wispelaere, 2016). The obvious solution would be to set up basic income experiments designed so as to yield the data necessary for testing the hypotheses that we are interested in.

However, such an experimental approach invites yet another question to be phrased in familiar terms: "what (if anything) can justify basic income experiments?" It is to this question that this essay proposes an answer. This answer will be a simple one: basic income experiments are justified if their expected benefits exceed their expected costs, whereby both are to be measured in terms of justice. The next section defends this proposal and expresses it in the form of a mathematical inequality. The four sections thereafter zoom in on each of the factors in the inequality and put forward suggestions for setting up UBI experiments in such a way that the standard proposed here is most likely to be met. The section that follows introduces and rebuts two criticisms of this paper's proposal, before the final section concludes.

\section{Justifying Basic Income Experiments}

The first thing to get straight when exploring the question what can justify basic income experiments, is what the word "justify" in this phrase actually refers to. At the most general level, to justify something is simply to give or to constitute a good reason for something. Crucially, the nature of the thing that is to be justified determines what counts as a good reason. If that thing is, say, the habit of keeping milk in the fridge, then a good reason could consist in past experiences with milk going bad when kept outside the fridge; if that thing is the choice for a certain lover, then a good reason could be how wonderful that person makes one feel. If the thing to be justified, however, is the decision to conduct a basic income experiment, I argue that a good reason cannot be any type of reason, but must be a reason of justice. This is because of the particular character of UBI on the one hand, and of UBI experiments on the other. Some elaboration is due. 
Let me start with UBI itself. Basic income is generally thought of as a policy that has the potential to make society more just. Justice must thereby be understood broadly. As the justificatory standard proposed in this paper is supposed to be helpful to researchers regardless of which particular conception of justice they hold, I will not provide a precise definition of the term here. Rather I treat justice as a heading under which we can bring a wide range of different values and principles, which many people feel to resonate with their deepest moral intuitions, but which different people may still work out in different ways: from liberty to equal treatment, from democracy to priority for the worst-off. As we will see, many thinkers have argued that basic income promotes ideals such as these.

I take it that these arguments for UBI can only be vindicated or rejected once the policy has been tried out in practice. Political philosophers can have all kinds of ideas about what would make society (more) just, but ultimately the proof of the pudding is in the eating. Borrowing a concept invented by Fung (2007), I say that we should find out whether the strongest theories of basic income are in pragmatic equilibrium, that is, whether the consequences of the institution they prescribe actually advance the values upon which the case for this arrangement was built.

This brings me to UBI experiments. In order to discover whether basic income would indeed improve society's level of justice, a logical step would be to test it out in practice. Some have pleaded for conducting basic income experiments in laboratory settings (Noguera \& De Wispelaere, 2009). Although such experiments might indeed yield important behavioural insights, I think they would be less suitable for uncovering the impact of UBI in terms of grand values such as freedom, equality, or democracy. In order to find an answer to the question whether basic income would really bring society any closer to such ideals, it would make sense to carry out a basic income experiment not in a laboratory but in a real-world setting. Ideally, such an experiment would involve an intervention in the context of an actually existing (micro-)society whereby people are actually supplied with a basic income for some time.

The interventional character of a UBI experiment like this, however, raises issues of justice of its own. Is it morally defensible to provide what seems to be a beneficial test treatment to some but not to others? To make people participate in a study without their consent? To run the risk of them getting accustomed to a benefit that they later again have to live without? ${ }^{2}$ Not to mention the amount of money to be spent on UBI experiments, which could probably be used to fight injustice in far more direct ways than through policy research.

2 I borrowed these examples from the website of UBIEXP: https://ubiexperiments.weebly.com/ aims-of-the-project.html. 
Given that justice forms such an important component of both the potential benefits of UBI and the costs that can accompany UBI experiments, I contend that conducting basic income experiments is justified if there are good reasons of justice for doing so. This does not yet tell us, however, what counts as a good reason of justice. I take the consequentialist view that there is a good reason of justice for an action if it is expected to have a positive net effect by the metric of justice. My central claim is thus that basic income experiments are justified if their expected benefits $(B)$ in terms of justice outweigh their expected costs $(C)$ in terms of justice. In its most general form, this standard of justification can be expressed as the inequality $B>C$.

This proposal can be seen as an application of White's (2009) well-known balance of fairness argument for UBI (pp. 4-6) to the case of UBI experiments. White's argument is meant as a rebuttal of one classic objection to the idea of an unconditional basic income: that such an income violates reciprocity because it is also paid to those who simply choose not to make any productive contribution to society. White's response is that even if basic income does have costs in terms of fairness because it violates reciprocity in this way, it also has benefits in terms of fairness because it protects people against market vulnerability. On balance, White suggests, basic income will simply prevent more injustice than it might create. In this paper, I take the standard that White applies to UBI - its benefits in terms of justice should outweigh its costs in terms of justice - and apply it to basic income experiments.

Let me now work out the $B>C$ standard for UBI experiments in more detail. What would the benefits and costs in question consist in? Starting on the benefitside, the expected benefits of a basic income experiment $B$ are determined by two factors. Firstly, the expected effect of the unconditional basic income on the level of justice attained in the context in which the policy is implemented. Let me bring this factor under the heading of $B_{\mathrm{ubi}}$ - in its simple form referring to the benefits in the context of the experiment, and when supplemented with an apostrophe referring to those in other contexts than the one of the experiment. Secondly, the expected potential of the experiment to encourage power-holders to implement the policy in these other contexts - I call this $P_{\text {exp }}$. We could say that the total expected benefits of a basic income experiment by the metric of justice, then, are formed by the justice UBI is thought to create directly, that is, among the participants who receive it in the experiment situation; plus the justice the experiment is thought to bring about indirectly, that is, by affecting the likelihood that the policy is introduced and thus improves the level of justice in real-world situations. In formulaform: $B=B_{\mathrm{ubi}}+P_{\mathrm{exp}} \times B_{\mathrm{ubi}}{ }^{\prime}$.

Moving over to the cost-side, the expected costs of a basic income experiment $C$ are made up of two major components. Firstly, remember the concerns that can 
come attached with the experimental intervention: handing out cash to one part of the population but not the other, subjecting people to a study without their consent, and giving them a benefit that they might get used to but that will be withdrawn later, all seem to involve some kind of injustice - let me put these costs under the heading of $C_{\text {int }}$. Secondly, given that the resources devoted to an experiment cannot be spent on remedying glaring injustices that can be observed around the world, such a study obviously comes with opportunity costs in terms of justice as well - I refer to these as $C_{\text {opp }}$. The total expected costs of a basic income experiment by the metric of justice can thus simply be expressed as follows: $C=C_{\text {int }}+C_{\text {opp }}$.

The justificatory standard for basic income experiments proposed here can now be presented as the inequality: $B_{\mathrm{ubi}}+P_{\mathrm{exp}} \times B_{\mathrm{ubi}}{ }^{\prime}>C_{\mathrm{int}}+C_{\mathrm{opp}}$. Some readers might not find this mathematical language to make for a very inspiring approach. When asking what (if anything) can justify UBI experiments, shouldn't we be talking about the promises and pitfalls of basic income, the questions that still lie before us about this policy, and the way experiments should be designed? of course we should, and we will. Rather than calling for us to take up our calculators, the mathematical sentence given here just serves as a starting point for figuring out under what circumstances basic income experiments are justified: it directs us to the factors that are important in this regard, and clarifies in what relation they stand to one another. Below I will thus elaborate each of these factors, explaining what determines their respective values, but without specifying how to express these numerically. Instead, I will be making suggestions about how researchers wanting to set up a basic income experiment may design it in such a way that it stands the most chance of meeting the standard for its justification.

\section{Benefits of Basic Income ( $\left.B_{\text {ubi }}\right)$}

Let me start with the factor $B_{\mathrm{ubi}}$, the effect that the institution of basic income is expected to have on the level of justice attained in the situation in which the policy is implemented. In other words, we are interested in how much more just a society will become as a result of the introduction of UBI. This effect factors into the expected benefits of basic income experiments twice: as a direct benefit in the experiment situation $\left(B_{\mathrm{ubi}}\right)$, and as an indirect benefit if basic income is later introduced also in real-world situations $\left(B_{\mathrm{ubi}}{ }^{\prime}\right)$. The expectation about UBI's effect on a society's level of justice - that is, the value of $B_{\mathrm{ubi}}\left({ }^{\prime}\right)$ - will vary with the philosophical viewpoint adopted and the specific version of the basic income scheme established. Let me explain. 
As was pointed out in the introduction, political philosophers have over time evaluated UBI in terms of a wide range of values that can be considered crucial components of justice. I highlight just a sample of these accounts here. Many of them approach the idea of basic income from the ideal of freedom. Each thereby defines both the policy and the value at hand in its own particular way. Van Parijs (1995) proposes a UBI that grants people the greatest possible opportunity to do whatever they might want to do, which he presents as a core component of "realfreedom-for-all” (p. 27). Widerquis (2013) advocates a UBI that provides people the effective power to accept or refuse active cooperation with willing others, which he claims to be necessary for ensuring "freedom as effective control self-ownership" (p. 15). And Raventós (2007) and Casassas (2007) consider a UBI granting people material independence, which they believe could promote the republican ideal of freedom as non-domination.

Other accounts examine the idea of UBI in light of the value of equality. Again, what kind of basic income scheme is envisaged and what form of equality is considered differs per account. Van Parijs's (1995) UBI, which redistributes opportunities over the members of society, has been said to fit the luck egalitarian ideal of equality of fortune (as criticised by Anderson, 1999). At the same time, Van Donselaar (2008) claims that Van Parijs's UBI, to which people are entitled regardless of their willingness to work, goes against the luck egalitarian position that people should bear the consequences of their voluntary choices. Birnbaum (2012) makes a relational egalitarian case for UBI, arguing that basic income enables people to exercise their basic liberties and gives them access to the bases of self-respect, which in turn forms a key requirement for the realisation of equality of status. Finally, Robeyns (2000) and Fitzpatrick (1999) consider UBI in light of the ideal of gender equality, both highlighting positive as well as negative effects that the policy could have on the position of women.

Surveying all of these arguments, it appears that they can be divided into three categories. Firstly, those in which UBI is presented as a way to really fulfill a certain ideal (in the accounts considered above, this would be some form of freedom or equality). Secondly, those in which UBI is instead found to clash with such an ideal. And thirdly, those that acknowledge there to be both upsides and downsides to UBI in terms of one or more ideals, and then make up the balance between the two - which is also White's (2009) approach in the balance of fairness argument mentioned previously. All in all, it seems that there exist various lines of argument leading to the conclusion that UBI would have a positive net effect in terms of justice - just like there are different avenues leading to the opposite conclusion.

Importantly, what argument can convincingly be made depends partly on the specifics of the UBI scheme at issue. Consider Alaska's Permanent Fund Dividend program, a unique example of a real-world basic income scheme (Widerquist \& 
Howard, 2012, p. 3). In recent years, this program entitled each Alaskan to about $\$ 1000$ to $\$ 1500$ annually. One might persuasively argue that this policy realises at least one aspect of equality of resources. This is in fact the thought behind the Alaska program: the payment gives all citizens an equal share of the returns on the state's oil revenues. But it is not plausible that a basic income of that amount grants people something as substantive as equality of status. To put it crudely: instituting a yearly gift of one or two thousand dollars per person is not going to turn your society into a community of equals. Thus we can see that whether and how far basic income can promote a certain ideal is affected by the height of the payment. The same applies to other details of the program. Think of the spreading of payments over time: a big yearly sum might give recipients more freedom than a small monthly award. Or eligibility criteria: a basic income for households might result in different gender dynamics than an individual allowance. In general, we can say that the effects of UBI by the metric of justice will vary with the particulars of the scheme at issue.

This is one of the reasons why it may sometimes be necessary to distinguish between the benefits that UBI is expected to yield in the context of the experiment $B_{\text {ubi }}$ - and the benefits that it is expected to generate later in some real-word context $-B_{\text {ubi }}{ }^{\prime}$. If the basic income scheme to be tested out in the experiment and the scheme that power-holders might get inspired to implement in the real world are expected to be of the same kind, and if the experimental context and the real-world context are reasonably comparable to one another, then we can assume these benefits to be more or less equal. If, however, the specifics of these schemes are expected to be quite different, or if these contexts vary a lot when it comes to factors such as culture or demographics, then these benefits - and hence the values of $B_{\mathrm{ubi}}$ and $B_{\text {ubi }}{ }^{\prime}$ - may come apart as well. I will return to this issue in the next section.

To wrap up, the expected net contribution of a UBI policy to the level of justice reached in the (micro-)society in which it is implemented - that is, the value of $B_{\text {ubi }}\left({ }^{\prime}\right)$ - depends on two things. Firstly, it will be higher or lower, positive or negative, depending on the theoretical perspective adopted. Secondly, it will vary with the specifics of the scheme implemented. Researchers hoping to set up a basic income experiment, then, will generally want to go for a version of the scheme that can be expected to contribute substantially to the realisation of the values that they take justice to consist in.

\section{Benefits of Basic Income Studies $\left(\boldsymbol{P}_{\exp } \times \boldsymbol{B}_{\mathrm{ubi}}{ }^{\prime}\right)$}

Now let me move on to the factor $P_{\text {exp }}$, the expected potential of a basic income experiment to encourage power-holders to actually implement the policy later. 
Where the previous section dealt with the benefits of UBI itself, the current one is concerned with the benefits of the UBI study. This shifts the focus entirely to the indirect benefits to be expected from experimental basic income research. These are determined by the impact an experiment is expected to have on the inclination of those in power to implement UBI in real-world situations, and the expected effect such an implementation of UBI would have on the level of justice attained in these situations - that is, the expected indirect benefits of an experimental basic income study by the metric of justice are constituted by $P_{\exp } \times B_{\text {ubi }}{ }^{\prime}$. As we just learnt, $B_{\text {ubi }}{ }^{\prime}$ varies with the philosophical viewpoint taken and the specifics of the basic income scheme implemented. The value of $P_{\text {exp }}$, on the other hand, depends primarily on the questions the study asks, the scientific quality of the study, and the connection between science and politics. Let me address each of these matters in turn.

The first of the things determining the impact of any research project is the choice for a certain set of research questions. UBI is a fascinating topic about which various interesting questions can be asked. In the previous section, we already learnt that political philosophers have raised and resolved many theoretical puzzles about the relationship between basic income and a number of important values. Furthermore, economists and other empirical researchers have made significant progress in exploring the practice of basic income, whereby some have indeed used experimental methods or data (see, for example, Davala, Jhabvala, Standing, \& Kapoor Mehta, 2015; Forget, 2011; Haushofer \& Shapiro, 2016). Those hoping to do UBI research with true impact would be wise to have a good look at what we already know about basic income from these studies, and think hard about which gaps in knowledge it would be most essential to fill.

As mentioned previously, I think there lies a particularly pressing task for UBI researchers to find out if the theories that present basic income as a key to liberty, equality, fairness, etcetera stand the test of pragmatic equilibrium. Does UBI really contribute to the realisation of ideals such as these? For example, considering the freedom-focused accounts of basic income mentioned earlier, it may be investigated whether the introduction of UBI does indeed make people experience more freedom to pursue the life options of their choice. Or, in light of relational egalitarian arguments for basic income, it could be examined if UBI actually encourages people to see and treat one another as equals. I already suggested that the most logical route to finding answers to questions such as these would be to carry out field experiments: experiments whereby UBI is introduced in an actually existing (micro-)society.

Once the choice for an experimental study has been made, the next factor determining its potential to influence future policy-making is the degree to which it meets the standards for good scientific research. The higher the study's scientific 
quality, the greater this potential. After all, it is generally the scientific quality of a study that determines its impact in the world of academia, and it is often the scholarly commendation for a study that determines its influence in the real world. Now, in the case of an experimental UBI study, making sure that it meets the standards for good scientific research might require some tough decisions, which will be flagged up in the next two sections.

The last determinant of a study's impact on real-world policies is the relationship between science and politics. For this relationship to be a fruitful one, two conditions are important. Firstly, scholars have to communicate their findings in a way that enlightens the public discussion (Widerquist, 2018). Secondly, powerholders have to be responsive to scientific evidence in policy-making. This last point is tricky. On the one hand, there is reason for researchers planning to conduct UBI experiments to be hopeful about the potential for their studies to influence real-world policies: policy-making on the basis of evidence from experiments seems to be on the rise (Cartwright \& Hardie, 2012). On the other hand, scholars should take seriously the possibility that their data will be instrumentalised by those in power to serve their own political agenda. It is not unimaginable, for example, that researchers find that one type of UBI scheme has a positive effect in terms of justice, and power-holders then ride the wave of this success to implement a different kind of basic income scheme that does not enhance justice. If researchers have reason to expect such a scenario to unfold, then the values of $P_{\exp }$ and $B_{\text {ubi }}$ may be high, but $B_{\text {ubi }}{ }^{\prime}$ may be so low (possibly even below zero) that the justifiability of the experiment is seriously compromised.

One final and related point to note is that a basic income experiment may not only inspire power-holders to embrace UBI in some form or the other, but it may just as well push them away from the idea. Indeed, if an experiment reveals that the policy actually has an undesirable impact, then it would in fact be a good thing if the study put people off from the plan. Importantly, researchers may anticipate this before the start of their experiment as well, which would in turn have consequences for the way in which they would fill in the mathematical sentence that is supposed to help them determine if their study is justified. Those with pessimistic expectations about UBI would probably fill in a negative value not only for $\left.B_{\mathrm{ubi}}{ }^{\prime}\right)$

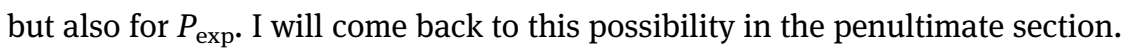

We can now draw a couple of conclusions about the expected impact of experimental basic income studies. Given the increasing reliance on experimental evidence in real-world policy-making, the absolute value of $P_{\exp }$ - that is, the expected potential of a basic income experiment to induce power-holders to implement UBI in real-world situations - is likely to surpass zero. This value can further be boosted if researchers aim at answering the most pressing question in the basic income debate at the moment - which I have argued to be whether UBI in 
practice promotes the values upon which the case for UBI in theory rests. Furthermore, when moving on, it is important to keep in mind that the absolute value of $P_{\text {exp }}$ falls rapidly as the scientific quality of a study is compromised. When we remember that, in order to calculate the expected indirect benefits of an experimental basic income study by the metric of justice, $B_{\mathrm{ubi}}{ }^{\prime}$ needs to be multiplied by $P_{\exp }$, it becomes clear what a pity that would be.

\section{Experimental Intervention and Its Costs $\left(C_{\text {int }}\right)$}

Now that we have an impression of the benefits that are expected to come with UBI experiments, let us move over to the cost side. Part of the costs that basic income experiments can cause by the metric of justice originate from the interventional character of such studies. The size of this cost component - that is, the value of $C_{\text {int }}$ - is determined by the sacrifices researchers can expect to make in terms of justice when they subject real people in a real society to a real UBI policy, even if it is only for the sake of a test. Let me illustrate.

Imagine a study in which a group of researchers randomly singles out from a certain society one sample of people who are made to participate in a UBI experiment for a substantial period of time. From the viewpoint of justice, such a procedure can be viewed as problematic in a number of ways. Firstly, it seems unfair that some people get a benefit and others do not for reasons that do not track their personal needs and are beyond their own control. Secondly, one can wonder if it is legitimate to subject people to an experiment without their consent. This could be deemed especially objectionable in light of a third point: those receiving an unconditional allowance during the experiment might over time come to rely on the income stream, and experience the eventual ending of the experiment as a harm to their interests. ${ }^{3}$

Researchers could, of course, take steps to design their experiment in such a way that these injustices would be mitigated. They might select participants on the basis of their personal need or special merit, to create some form of fairness in the selection of UBI recipients. They might also ask people for their explicit consent before subjecting them to the experiment, so as to avoid the charge of illegitimacy. And they might go for a shorter test period, in order to prevent recipients from getting used to a benefit that they will lose again later. However, there is a significant downside to measures such as these: they could come at the cost of the scientific quality of the study. In order to prevent selection bias and safeguard the

3 I repeat that the source of these examples is https://ubiexperiments.weebly.com/aims-of-theproject.html. 
external validity of the research findings, for example, it may be important to select participants, or communities of participants, in random fashion (see Standing, 2012, pp. 138-140 for some thoughts on this). And in order to gain proper insight into the workings and effects of the policy and secure the reliability of the observations, it would be wise to opt for a longer test period. Thus, researchers can face a dilemma between avoiding the injustices that can accompany their experimental intervention, and meeting the highest standards for good scientific research.

Now remember from the previous section that the scientific quality of a UBI experiment is an important determinant of its impact on future policy-making. Thus we can see that efforts to mitigate the injustices the experimental intervention is expected to create, by compromising the degree to which the study meets the standards for good scientific research, could in fact undermine its function as a basis for policy-making in the future. In other words, attempts to curtail the value of $C_{\text {int }}$ might simultaneously squeeze the value of $P_{\text {exp }}$. Researchers who wish to conduct justifiable UBI experiments should try to strike the right balance between both factors.

\section{Opportunity Costs of Basic Income Experiments $\left(C_{\text {opp }}\right)$}

The second component of the costs in terms of justice expected to come attached with basic income experiments, and the last factor in the inequality representing the justificatory standard for these experiments, concerns the opportunity costs of these experiments. The amount of the costs in question - that is, the value of $C_{\mathrm{opp}}-$ is equal to the amount of injustice that could have been wiped off the surface of the Earth had the resources devoted to the experiment been spent on fighting wrongs other than people not receiving a UBI. Let me elaborate on this point briefly.

Research projects generally cost money, time, and effort. This also applies to basic income experiments. In fact, as they typically involve paying people significant sums of cash, UBI experiments can be expected to require relatively high expenses. As money, time, and effort can only be spent once, if these resources are devoted to UBI experiments, it means that they are not spent on remedying some obvious injustices that can be observed around the world - say, sweatshop labour, female genital mutilation, and persecution of religious minorities. The increase in the overall level of justice that could be achieved if resources were directed at fighting such wrongs instead of conducting a UBI experiment make up the experiment's opportunity costs by the metric of justice. 
Of course, the higher the expenses of a basic income experiment, the higher the opportunity costs in question. Researchers could thus reduce opportunity costs by cutting back on their spending for the experiment. This could be done, for example, by decreasing the number of people who receive a UBI, or by lowering the sum of the UBI they receive. However, just like the measures discussed in the previous section, efforts to cut down expenses could (paradoxically) come at a cost. For in order to test whether UBI makes a real contribution to the realisation of the values it is supposed to promote, the payment must be set at a certain level. And in order to generate enough data for drawing reliable conclusions about the effects of UBI, it has to be tested out on a sufficiently large body of participants. Again, researchers might face a dilemma: lowering the experiment's opportunity costs in terms of justice, versus going for a higher UBI and more participants, which could make the study provide better insight into the policy's real potential for promoting justice.

Once more, researchers hoping to conduct a UBI experiment must find the right equilibrium between different factors. This time, the choice is between cutting back on the expected opportunity costs of the experiment in terms of justice, and increasing the expected effect of the policy on the level of justice in the context in which it is implemented, as well as the potential of the experiment to affect future policy-making for real-world contexts. In other words, there is a trade-off between curtailing the value of $C_{\text {opp }}$ on the one hand, and boosting that of $B_{\mathrm{ubi}}\left({ }^{\prime}\right)$ and $P_{\exp }$ on the other. Again, there is a balance to be struck.

\section{Criticisms}

This essay started out with the thesis that basic income experiments are justified if their expected benefits by the metric of justice exceed their expected costs by the metric of justice. In the form of a mathematical inequality: $B_{\mathrm{ubi}}+P_{\mathrm{exp}} \times B_{\mathrm{ubi}}{ }^{\prime}>C_{\mathrm{int}}+C_{\mathrm{opp}}$. After that, we zoomed in on the factors that make up the benefits and costs in question. Respectively: the expected effect of UBI on the level of justice attained in the context where the policy is implemented $\left(B_{\mathrm{ubi}}\left({ }^{\prime}\right)\right)$, the expected potential of the experiment to encourage power-holders to implement the policy in other contexts too $\left(P_{\text {exp }}\right)$, costs in terms of justice that can be expected to come attached with the interventional character of the experiment $\left(C_{\text {int }}\right)$, and expected opportunity-costs by the metric of justice $\left(C_{\text {opp }}\right)$. Now, zooming out again, new critical questions about the general approach taken here might be raised. Let me discuss two.

The first question considers the consistency of my claims. On the one hand, I put the expected effect of UBI on the level of justice achieved in the context in which it is implemented $\left.\left(B_{\mathrm{ubi}}{ }^{\prime}\right)\right)$ on the benefit-side, and call it a " $B$ " (from 
"benefit"), not a " $C$ " (from “cost"). On the other hand, my discussion of the test of pragmatic equilibrium suggests that we cannot know for sure whether a policy actually does promote a certain value (possibly justice, or a value that can be seen as a part of justice) until it has been tried out in practice. Don't I, then, assume something - namely, that basic income contributes to justice - that still has to be established?

Let me start by acknowledging that the exact effects of UBI, by various metrics including that of justice, are still unsure. This is why I refer to the expected effect of basic income in the standard I propose, and this is why I claim that it is important to subject the theoretical arguments for basic income to the test of pragmatic equilibrium. I do believe that it makes more sense to conduct a UBI experiment if the expectation is that UBI would have a positive effect in terms of justice. Nonetheless, if basic income is expected to have a negative effect on the level of justice attained in the context in which it is implemented, my proposal perfectly allows for filling in a negative value for $B_{\mathrm{ubi}}\left({ }^{\prime}\right)$. Note that, in this case, a UBI experiment that asks the right questions and is properly conducted would likely make powerholders less rather than more inclined to introduce UBI in the real world, resulting in a negative value of $P_{\text {exp. }}$. Interestingly, a basic income experiment could then still be justified: if the expectation is that the study will play a crucial role in preventing those in power from making the huge mistake of implementing this putatively unjust policy (that is, multiplying the negative values of $P_{\exp }$ and $B_{\text {ubi }}{ }^{\prime}$ yields a high positive value), then the injustice occurring in the (micro-)society of basic income recipients in the experiment $\left(B_{\mathrm{ubi}}\right)$ and the injustice related to the experimental intervention $\left(C_{\text {int }}\right)$ and opportunity costs $\left(C_{\text {opp }}\right)$ might indeed be offset.

The second critical question my proposal may give rise to concerns its practical use. The impression might be that, in order to apply my standard of justification for basic income experiments, one needs to quantify in absolute numbers both expected effects in terms of justice $\left(B_{\mathrm{ubi}}\left({ }^{\prime}\right), C_{\text {int }}\right.$, and $\left.C_{\text {opp }}\right)$ and expected impact $\left(P_{\text {exp }}\right)$, whereas actually these things do not take numerical values, or, at any rate, it is impossible for human beings to establish these values. Doesn't this show, then, that my standard is of no practical use whatsoever?

Let me first of all agree that, at least in practice, the factors in my mathematical sentence cannot be quantified in absolute numbers. I do, however, think it possible to tell whether the values these factors take are positive or negative, and high or low compared to one another. Let me borrow Sen's mountain metaphor (Sen, 2009, p. 102) and say that people should be able to tell the difference between Mount Kilimanjaro and Mount McKinley, even if they do not know their peak heights in meters. Similarly, I believe that people should be able to compare the expected opportunity costs and costs related to the interventional character of UBI experiments on the one hand, and their direct and indirect benefits on the other, 
simply by using their intuitions about justice. Therefore, anyone willing to engage in some serious moral reflection should be able to get some wiser about the question whether basic income experiments are justified - or whether a particular basic income experiment is justified - by using the standard proposed here. Finally, even if that exercise still turns out to be unfeasible, at the very least this paper shows which are the core factors determining whether UBI experiments are justified, how they interact with one another, and what researchers might do to influence their value and make the experiment they are planning more justifiable.

\section{Conclusion}

So, what (if anything) can justify basic income experiments? I have suggested that basic income experiments are justified if their expected benefits exceed their expected costs, both measured in terms of justice. What does this mean for researchers hoping to carry out a UBI experiment? I have recommended that those who want to make their experiment pass the threshold for justification, firstly, opt for a version of the basic income likely to contribute substantially to the realisation of the values they associate with the term "justice". Secondly, they are advised to ask the questions that need answering most, that is, questions about the pragmatic equilibrium of the strongest theories of UBI. Lastly, although it might be tempting to try and set up the study in such a way as to minimise injustices related to the experimental intervention and the opportunity costs of the project, they should be careful not to undermine the potential of the experiment to inspire future policies, or the benefits with which basic income is hoped to come attached in the first place. Let me end by encouraging researchers to take the costs that do inevitably accompany UBI experiments not as a reason not to conduct them at all, but indeed as an incentive to make them worth it. For it would be a shame never to find out if basic income can make true in practice the promises of justice so many have made in theory.

\section{References}

Anderson, E. (1999). What is the point of equality? Ethics, 109(2), 287-337.

Birnbaum, S. (2012). Basic income reconsidered: Social justice, liberalism, and the Demands of equality. New York: Palgrave Macmillan.

Cartwright, N., \& Hardie, J. (2012). Evidence-based policy: A practical guide to doing it better. Oxford: Oxford University Press.

Casassas, D. (2007). Basic income and the republican ideal: Rethinking material independence in contemporary societies. Basic Income Studies, 2(2), 1-7. Article 9. 
Davala, S., Jhabvala, R., Standing, G., \& Kapoor Mehta, S. (2015). Basic income: A transformative policy for India. London: Bloomsbury.

De Wispelaere, J. (2016). Basic income in our time: Improving political prospects through policy learning? Journal of Social Policy, 45(4), 617-634.

Fitzpatrick, T. (1999). Freedom and security: An introduction to the basic income debate. London: Palgrave Macmillan.

Forget, E. L. (2011). The town with No poverty: The health effects of a Canadian guaranteed annual income field experiment. Canadian Public Policy, 37(3), 283-305.

Fung, A. (2007). Democratic theory and political science: A pragmatic method of constructive engagement. American Political Science Review, 101(3), 443-458.

Haushofer, J., \& Shapiro, J. (2016). The short-term impact of unconditional cash transfers to the poor: Experimental evidence from Kenya. The Quarterly Journal of Economics, 131(4), 1973-2042.

Noguera, J. A., \& De Wispelaere, J. (2009). A plea for the use of laboratory experiments in basic income research. Basic Income Studies, 1(2), 1-8.

Raventós, D. (2007). Basic income: The material conditions of freedom (J. Wark (trans.)). Pluto Press.

Robeyns, I. (2000). Hush money or emancipation fee? A gender analysis of basic income. In Van der Veen, R., \& De Groot, L. (Eds.), Basic income on the agenda: Policy objectives and political chances (pp. 121-136). Amsterdam: Amsterdam University Press.

Sen, A. (2009). The idea of justice. London: Penguin Books.

Standing, G. (2012). Basic income pilot schemes: Seventeen design and evaluation imperatives. In Jacobi, D., \& Strengniann-Kuhn, W. (Eds.), Wege zum Grundeinkommen (pp. 133-152). Berlin: Bildungswerk Berlin der Heinrich-Böll-Stiftung.

Van Donselaar, G. (2008). The Right to exploit: Parasitism, scarcity, basic income. Oxford: Oxford University Press.

Van Parijs, P. (1995). Real Freedom for all: What (if anything) can justify capitalism? Oxford: Oxford University Press.

White, S. (2009). Reconsidering the exploitation objection to basic income. Basic Income Studies, 1(2), 1-17. Article 4.

Widerquist, K. (2013). Independence, propertylessness, and basic income: A theory of freedom as the power to say no. New York: Palgrave Macmillan.

Widerquist, K. (2018). A critical analysis of basic income experiments for researchers, policymakers, and citizens. Cham: Palgrave Macmillan.

Widerquist, K., \& Howard, M. W. (2012). Introduction: Success in Alaska. In Widerquist, K., \& Howard, M. W. (Eds.), Alaska's permanent fund dividend: Examining its suitability as a model (pp. 3-11). New York: Palgrave Macmillan. 